\title{
LA PARTICIPACION Y LA COLABORACION CIUDADANAS EN LA GESTION MUNICIPAL, COMO DEMANDAS DE LA HORA ACTUAL (")
}

35.072 .7

por

Julián Carrasco Belinchón

SUMARIO: I. PRESENTACION.-II. INTRODUCCION--III. PARTICI-

PACION CiUdadana: 1. Planteamiento. 2. La Calidad de la Vida COMO OBJetivo. 3. Las demandas de lá mujer como ciudadana. 4. ParTICIPACIÓN CIUDADANA. 5. DISEÑO HEURISTICO DE LA PARTICIPACION:

A) Participación antes de la adopción de las principales decisiones.

B) Participación en el control de las actuaciones municipales.-IV. COLABORACION CIUDADANA.-V. CONCLUSION.

\section{PRESENTACION}

Mis primeras palabras son para expresar mi agradecimiento a la Junta de Gobierno de este Colegio provincial, por invitarme a ocupar hoy esta tribuna y con ello tener nuevamente la satisfacción de encontrarme en esta ciudad, a la que tan estrechamente me siento unido, para manifestar mi gratitud por las palabras de presentáción, y para exteriorizar mi reconocimiento a las autoridades que nos presiden y que con su presencia nos honran a todos.

Cuando nuestro común y querido amigo y compañero Elías OrTIz me propuso intervenir en este acto, tuve dudas en aceptar, pensando que por haber disertado ya en otras ocasiones aquí, mi

(*) Texto literal de la conferencia pronunciada en el Colegio Oficial Provincial de Secretarios, Interventores y Depositarios de Málaga, el 15 de octubre de 1977 : 
nueva aparición podía implicar una reiteración ante vosotros y un abuso de vuestra paciencia, pero después estimé, por un lado, que la paciencia la tenéis debidamente acreditada en el cotidiano quehacer profesional; por otro lado, que me habéis dado reiteradamente muestras de vuestra auténtica amistad $\mathrm{y}$, por último, que al intervenir tenía ocasión de testimoniar el sincero afecto que siento hacia vuestro Presidente, que sé que todos y cada uno de vosotros compartís. En conclusión, mi presencia hoy aquí es un símbolo de amistad común, que considero debe ser una constante en el sentir y en el actuar de cuantos integramos los Cuerpos Nacionales de Administración Local.

\section{INTRODUCCION}

En octubre de 1969, en un acto similar al actual, tuve la oportunidad de dirigirme a vosotros, disertando sobre el tema «Técnica y humanismo en la gestión local», afirmando como conclusión, que tanto el funcionario como el administrado son seres humanos, por los que hay que sentir una sincera preocupación, y que en la medida en que esta preocupación sea auténtica, actuaremos conforme al humanismo verdadero, el que es esencial, ya que de nada nos vale la técnica, si no es para servir, y servir cada vez mejor a nuestros conciudadanos, a los que nos debemos, por una obligación profesional y por un deber moral. En definitiva, finalizábamos diciendo que debemos buscar la técnica, que nos es útil, pero hay que aplicarla con sentido humano, ya que en otro caso se convierte en instrumento de explotación, lo que debe ser herramienta de liberación.

Un año después, en este mismo marco, tuve el honor de volver a disertar, en esa ocasión sobre el tema «Las Corporaciones locales ante una nueva sociedad", que era una continuación y una profundización sobre la misma problemática, si bien centrando la atención primordialmente en la relación con los vecinos y en el papel de éstos en la misma. Y así, concluíamos manteniendo que el reto al que habian de hacer frente las Corporaciones locales ante la nueva sociedad era: o se transformaban en órganos dinámicos y eficaces al servicio de la comunidad, o se convertían en simples oficinas locales de la Administración estatal, encargadas de recibir escritos y de distribuir notificaciones. Y; añadíamos, que 
es cierto que la transformación en órganos dinámicos requiere cauces adecuados y recursos suficientes, pero también precisa de estructuras y métodos apropiados, de dirigentes eficaces y de participación popular. Lo primero nos lo han de dar, pero lo segundo lo hemos de conseguir con nuestro propio esfuerzo y tesón. Ante este desafío, afirmaba, me siento profundamente optimista, pues si en definitiva todo depende del hombre, el hombre que está en la Administración local tiene unas cualidades excepcionales, tan excepcionales que le han permitido continuar en ella en épocas de soledad; de aquí que ahora, en momentos de esperanza, sea capaz de hacer hoy lo difícil y mañana lo imposible.

Desde estas últimas palabras mías han transcurrido siete años y han ocurrido en España en este intervalo muchos acontecimientos que están en la mente de todos y que determinaron que la ilusión con la que concluía mi disertación no se convirtiese en realidad. Ahora, la nueva etapa iniciada, hay que reconocer que si bien abre posibilidades inmensas, entraña también grandes problemas y suscita igualmente hondas preocupaciones. Lo que significa que demanda, en fin, un gran esfuerzo de imaginación para hallar soluciones idóneas; una firme voluntad de trabajo para llevarlas a la práctica; un auténtico espíritu de solidaridad para actuar conjuntamente $\mathrm{y}$ un sincero ánimo de comprensión para superar diferencias, para eliminar divergencias y para reducir antagonismos. Sólo mediante una acción inteligente, tesonera, mancomunada y con sentido humano, podremos afrontar dichos problemas que se nos presentan en el horizonte; podremos disipar esas preocupaciones que nos inquietan, y podremos aprovechar fecundamente tales posibilidades que se vislumbran.

Nuestro propósito; en el presente caso, es precisamente el poner de manifiesto la vigencia de las tesis que expusimos en las dos ocasiones reseñadas, así como también resaltar cómo las mismas pueden ser el punto de partida del planteamiento que vamos a desarrollar, al sostener la proposición de «La participación y la colaboración ciudadanas en la gestión municipal, como demandas de la hora actuals. 


\section{PARTICIPACION CIUDADANA}

\section{Planteamiento}

Si centramos, como punto de partida, nuestra atención en el vecino, es decir, en esa mujer y en ese hombre que son al mismo tiempo ciudadano, administrado y usuario de unos servicios municipales, ¿qué es lo que real y verdaderamente le preocupa en la hora actual? Podríamos afirmar, en síntesis, que, por una parte, desea contar con unos servicios eficientes que satisfagan adecuadamente sus crecientes necesidades; y, por otra parte, que se haga factible su realización personal dentro de la comunidad en la que vive y en la que se interrelaciona.

Si esto es así, y lo creemos verdadero, es evidente que la primera aspiración suscita problemas de adecuación de los servicios municipales a sus necesidades; en tanto que la segunda aspiración entraña la articulación de vías de protagonismo. Por otra parte, la atención a la primera aspiración implica un ajuste en la dialéctica técnica-humanismo; mientras que satisfacer la segunda aspiración supone hallar cauces de participación que amplíen y que complementen los procedimientos políticos de representación.

En definitiva, pensamos que cabe sostener que la primera aspiración demanda la previa consideración de cuáles son las necesidades actuales de la mujer y del hombre que forman parte de la comunidad vecinal y que pueden ser atendidas a través de los servicios específicos de la organización en la que se estructura aquélla. En tanto que la segunda aspiración significa que hay que contemplar los procedimientos de representación política para buscar sistemas y métodos que los complementen y que hagan posible una participación auténtica y permanente de los vecinos en la vida de las Corporaciones municipales.

\section{LA CALIDAD DE LA VIDA COMO OBJETIVO}

Si nos fijamos en el primer aspecto, no es fácil poder sintetizar el conjunto de demandas de las mujeres y de los hombres que integran cada comunidad municipal, pues el desarrollo social y la elevación del nivel de vida van progresivamente ampliando el nú. 
mero de exigencias, y van al mismo tiempo transformando éstas en una pretensión de un mayor grado de perfección. De tal forma, que hay que reconocer que ya no es sólo un simple problema cuantitativo: necesidades a atender $\mathrm{y}$, como consecuencia, servicios a prestar; sino que es, sobre todo, un problema cualitativo, es decir, de calidad.

En este sentido, cabe destacar cómo recientemente la OCDE ha llegado a la conclusión de que la sociedad de hoy lo que reivindica con más interés es la calidad de la vida, concretando las aspiraciones en este orden en veintiún puntos, que si bien no todos, ni mucho menos, pueden ser atendidos por las Corporaciones municipales, sí todos ellos han de ser tenidos en cuenta por las mismas, para conseguir que las instancias superiores - provincial, regional o estatal- les presten el cuidado que merecen y que requieren. Estos veintiún puntos, agrupados sistemáticamente, son los siguientes:

- Aplicación equitativa de la ley.

- Participación en la vida colectiva.

- Participación en las decisiones referentes a su vida familiar y laboral.

- Garantía de poder participar normalmente en la vida política, económica, social y cultural.

- Garantías contra la agresividad exterior.

- Igualdad de oportunidades para la formación profesional y para el desarrollo de las actividades profesionales.

- Seguridad de acceso a la cultura y de poder desarrollar la personalidad en función de esa cultura.

- Defensa de la herencia cultural, considerando a ésta como un elemento esencial de la calidad de la vida.

- Posibilidades de tener acceso abierto a actividades superiores, bien jerárquicas, bien lucrativas.

- Lucha contra las desigualdades sociales.

- Mejores garantías respecto a la calidad del trabajo.

- Garantía de una asistencia sanitaria adecuada.

- Protección del individuo y de la familia contra los riesgos económicos.

- Acceso normal a los servicios. 
- Derecho inalienable a la propiedad.

- Calidad de la vivienda.

- Facilidades para tener un mínimo de libertad en el empleo del tiempo.

- Derecho al reposc y a las vacaciones.

- Defensa de la vida privada.

- Respeto a un medio ambiente lo más óptimo posible para el individuo.

- Defensa del medio ambiente y protección de la población contra los riesgos de contaminación del mundo moderno.

Hay que reconocer que la simple enumeración de estos puntos pone de manifiesto que con sólo algunos de ellos se podría diseñar un amplio plan de objetivos a alcanzar en el ámbito municipal. Las limitaciones de tiempo nos impiden, como sería nuestro deseo, detenernos para glosar los mismos.

\section{LAS DEMANDAS DE LA MUJER COMO CIUDADANA}

Sí queremos, por otra parte, descender a un mayor detalle y tomamos como centro de atención a la mujer como miembro integrante de la comunidad municipal, por cuanto sus específicas necesidades requieren un cuidado preferente, no sólo por su elevado número, sino, primordialmente, por su trascendente misión en aquélla y por el relevante papel que en la misma le corresponde. A este respecto, podemos destacar las siguientes ideas, aportadas por el Comité del Trabajo Femenino del Ministerio francés de Trabajo, en dos informes recientemente publicados, $\mathbf{y}$ de los que reseñamos las siguientes propuestas de medidas a adoptar en el ámbito municipal:

- Implantación de guarderías infantiles y de comedores escolares, adecuadamente situados, contando con el respaldo financiero estatal.

- Organización de actividades educativas y de empleo del ocio para los niños en lugares apropiados. En este sentido, se mencionan las experiencias danesa, holandesa y suiza, como más relevantes. 
- Estructuración eficiente de los transportes urbanos, cuidando en especial los de la periferia y los que pongan en comunicación ésta con los núcleos principales de centros de trabajo.

- Organización de los Servicios de Asistentes Sociales para que presten su colaboración a las mujeres que desarrollan actividades laborales.

- Atención especial a la calidad de las viviendas. Tratando, al mismo tiempo, que en los mismos diseños se dediquen espacios para el ocio de los niños y de los adultos.

- Implantación de servicios colectivos de vecindad con carácter económico: limpieza y reparación del hogar, limpieza y conservación de ropas y vestido y preparación de la comida.

- Creación de residencias para transeúntes, de centros de higiene y de establecimientos similares que no sólo atiendan necesidades físicas, sino que también fomenten la convivencia.

- Establecimiento de horarios comerciales compatibles con la jornada de trabajo.

- Creación de instituciones culturales: bibliotecas, casas de cultura, etc.

En estos puntos, mencionados simplemente por vía de ejemplo, se aprecia una gran preocupación por atender áreas que tradicionalmente han sido soslayadas, y que, sin embargo, cada día revisten un mayor interés, por referirse a necesidades sentidas cada vez con mayor intensidad por grupos crecientes de población, como consecuencia de las mutaciones que se van operando en el género de vida de los mismos, merced a la dinámica sociolaboral.

Finalmente, hay que destacar que por nuestra parte, y sin pretensiones exhaustivas, podríamos añadir otros servicios igualmente relevantes y que reclaman una atención acusada: cuadas.

- Limpieza viaria y recogida domiciliaria de basuras, ade-

- Pavimentación correcta.

- Parques y jardines atendidos.

- Ordenación del tráfico y protección del peatón, mediante la señalización y semaforización apropiadas, así como a través de pasos elevados y subterráneos. 
- Alumbrado conveniente.

- Mercados, autoservicios, galerías de alimentación y establecimientos similares, racionalmente situados.

- Conservación eficiente de monumentos históricos y artísticos.

En conclusión, y para terminar el primer aspecto al que nos referíamos, podríamos afirmar, como manifestamos en mayo pasado en Fuengirola, que la gran meta que se ha de pretender es hacer más humana la convivencia ciudadana Lo que se polariza en tres grandes exigencias, en cuyo logro ha de esforzarse la política municipal:

- Crear y mantener un clima psíquico satisfactorio en las poblaciones para que éstas sean lugares de armonía y de cooperación, en vez de que sean marcos de enfrentamiento, campos de antagonismo y ocasiones de malhumor. Se ha de luchar por evitar «la jungla de asfalto».

- Conseguir y conservar una dimensión física apropiada de las ciudades sin gigantismos perturbadores ni núcleos insuficientes para atender las necesidades actuales. El equilibrio en el crecimiento horizontal, y las limitaciones en el vertical, han de ser preocupaciones permanentes.

- Lograr un ambiente atmosférico adecuado en el que desaparezcan las crecientes amenazas de la contaminación, lo que supone tanto una política reguladora de las instalaciones industriales, como una política fiscalizadora en el uso de combustibles y una política de control de tráfico rodado.

\section{PaRTICIPACIÓN CIUDADANA}

Si ahora pasamos al segundo aspecto al que nos referíamos, es decir, el de la participación ciudadana, estimamos que como cuestión previa es conveniente que nos fijemos en su problemática general para acto seguido poder matizar sus características y exigencias concretas en la realidad española. La problemática general entendemos que se centró en sus justos límites hace ya varios años. En concreto, en la ciudad de Zagreb en 1971, con motivo de la Conferencia de la Unión Internacional de Poderes Locales (I.U.L.A.), 
en la que se destacaron algunos de los principales problemas existentes en torno a la misma y se sugirieron las pertinentes soluciones.

Así, se comienza afirmando que la participación de los administrados en los asuntos locales constituye ya en numerosos países una realidad política que está en trance de extenderse a otras $\mathrm{Na}$ ciones, y que la misma, entendida como influencia de los administrados sobre los asuntos públicos, es el viejo problema de la democracia, que si ha adquirido tanta actualidad, es primordialmente por estos dos motivos:

1. La complejidad creciente de los problemas técnicos y administrativos que han de afrontar los poderes locales, que amenaza con arrastrar al hombre y a todas las comunidades humanas a una sociedad desenraizada y' deshumanizada.

2. El carácter impersonal del mecanismo administrativo como consecuencia del crecimiento económico que amenaza el ambiente, lo que demanda una mayor participación ciudadana en los asuntos públicos locales.

En segundo lugar, por una parte, se estima que la participación no tiene razón de ser más que cuando existe un sistema que permita la toma de decisiones en problemas importantes en el escalón local, lo que sucede cuando el público se encuentra personal y directamente afectado; $\mathrm{y}$, por otra parte, se entiende que los Consejos de Vecindad, si bien refuerzan el espíritu de comunidad en los planos municipales inferiores, produce a veces el efecto de desunir la solidaridad del nivel municipal superior, lo que puede suscitar la separación racial o social.

En tercer término, se advierte que no basta con limitarse a buscar nuevas fórmulas institucionales. Lo que existe es, más bien, una mayor necesidad de nuevos cauces a formas más adecuadas y espontáneas de participación. En este sentido, se afirmó que «se trata de descubrir el equilibrio necesario entre la postura espontánea y el espíritu de confrontación que emana del ciudadano, por una parte, y el mecanismo rígido que permita a la participación funcionar en el marco institucional, por otra. Se precisa una gran flexibilidad al mismo tiempo por parte del ciudadano como por la Administración para que el proceso de participación de aquél pueda ser eficaz». 
En cuarto lugar, se propugna la modificación del procedimiento actual de toma de decisiones, con ayuda de diversos medios, tales como:

- Proveer de poderes ( $y$ de posibilidades financieras) de mayor amplitud a los grados inferiores de la Administración.

- Proceder a una descentralización interna, particularmente en las grandes ciudades. La participación de un mayor número de ciudadanos debería compensar costos más elevados y procedimientos más largos.

- Redistribuir las tareas entre todos los planos administrativos, con el fin de simplificar el proceso de la teoría de decisión y hacerlo comprensible.

- Reducir al mínimo los debates y los documentos que deban ser secretos.

Finalmente, se reconoce que sería preciso en cuanto a los diversos grupos implicados en la adopción de decisiones:

- Asegurar la información de los ciudadanos sobre sus derechos y las posibilidades que les son brindadas.

- Impulsar la educación cívica.

- Favorecer la comunicación en los dos sentidos entre Concejales y partidos políticos, por una parte, y los administrados por otra.

- Forzar a los funcionarios técnicos a que adquieran conciencia de sus responsabilidades hacia la sọciedad y, si es posible, ayudar en la búsqueda de soluciones alternativas.

- Descubrir y eliminar la influencia y las presiones injustificadas que ejerzan «los grupos financieros y. económicos» (la especulación del suelo constituye uno de los peores' ejemplos).

En definitiva, en esta Conferencia se puso de relieve la necesidad de hallar fórmulas que hagan posible una participación efectiva de los ciudadanos en la vida municipal y se sugirieron criterios orientadores para la articulación de la misma. 


\section{Diseño heuRfSTico de La PARTicipación}

Frente a este planteamiento general que nos brinda dicha Conferencia, ¿cuál podría ser su vertebración concreta en la realidad sociopolítica de la España de 1977? Evidentemente, pueden existir diversas fórmulas, más o menos acabadas y más o menos perfiladas desde un punto de vista técnico y desde un plano teórico. Ahora bien, entendemos que mejor que decidirnos por cualquiera de ellas, es el inclinarnos por un diseño heurístico, que tiene como base las aportaciones y las sugerencias de un grupo selecto de mujeres españolas, políticas y funcionarias locales, que respondieron en la pasada primavera a una encuesta que preparamos para elaborar con las contestaciones las ponencias de la IV Reunión del Gabinete de Estudios de los Problemas de la Mujer en la Gestión Local, que sobre el tema "Humanización de la vida ciudadana como meta de la política municipal», proyectábamos celebrar por aquellas fechas en Huesca y que va a tener lugar en la ciudad de Vitoria a finales del mes de octubre.

Las ideas aportadas, que en su conjunto constituyen una valiosa contribución por su acusado realismo y por su profundo rigor, son al mismo tiempo un testimonio manifiesto de la gran preparación, de la verdadera preocupación y de la auténtica responsabilidad de la mujer española, a la que aquí y ahora deseo rendir un sincero tributo de admiración y de reconocimiento. Estas ideas, sin perjuicio de ser utilizadas para su fin primordial: la elaboración de las respectivas ponencias por parte de las mujeres encargadas de este cometido, nos van a servir también a nosotros para esbozar no sólo un programa de participación, sino también un proyecto de colaboración ciudadana en la vida municipal, que son, en definitiva, el tema objeto de esta disertación.

En la participación ciudadana podemos distinguir, a nuestro juicio, dos modalidades distintas: una, la participación antes de la adopción de las principales decisiones, y otra, la participación en el control de las actuaciones municipales; pues si bien ambas responden a una misma motivación: la necesidad del protagonismo ciudadano, fundado no sólo en el deseo de intervenir activamente en el gobierno y en la gestión de los intereses comunitarios, sino también en la exigencia, cada día más acuciante, de humanizar y de flexibilizar la acusada tecnificación y la tendencia al 
gigantismo de los servicios públicos que amenazan la libertad del ser humano, como se puso de manifiesto en la reseñada Conferencia de Zagreb; sin embargo, hay que reconocer que una y otra presentan peculiaridades propias que demandan un adecuado tratamiento específico.

A) Participación antes de la adopción de las principales decisiones

Si nos referimos a la primera modalidad, pensamos que nuestra atención debe centrarse en tres grandes puntos: cuestiones sobre las que debe versar, procedimientos para llevarla a cabo y métodos de articulación.

En primer lugar, estimamos que las cuestiones sobre las que es indispensable la participación para lograr conjuntamente una mayor calidad en las decisiones adoptadas, un ajuste más completo de las mismas con los deseos de los posibles afectados con ellas y una aceptación mayoritaria de éstos con respecto a tales decisiones, son todas aquellas de interés general o de gran trascendencia que involucren a determinados sectores de población o a áreas territoriales concretas. En especial, se pueden mencionar por su entidad o repercusión: por una parte, todas las referentes a planes de ordenación urbana; por otra parte, todos los proyectos de asentamiento y dotación de servicios de equipamiento comunitario: mercados, centros docentes, culturales, sanitarios y asistenciales, guarderías infantiles y residencias de ancianos, instalaciones deportivas, parques y jardines, transportes urbanos, saneamiento y vialidad; y, por otra parte, en fin, las relativas a normas reguladoras de instalación de industrias, en orden a sus aspectos de incomodidad, de peligrosidad o de toxicidad públicas.

En segundo lugar, en cuanto a los procedimientos para efectuarse la participación, consideramos que debe ser, tanto a título individual y familiar, como a través de asociaciones de vecinos, de amas de casa, de cabezas de familia, de padres de alumnos, de colegios profesionales, de entidades culturales y deportivas, de comunidades de propietarios, etc., según cada caso y la naturaleza del interés implicado en la decisión.

Hay que destacar que de todas estas entidades, son precisamente las asociaciones de vecinos las que pueden asumir una tarea más relevante, por lo que estimamos conveniente ocuparnos mo- 
mentáneamente de ellas, pues a partir de este momento nos vamos a fijar en las mismas con frecuencia, por entender que pueden desempeñar un papel importante como vehículo eficiente de la participación.

Ahora bien, en nuestro criterio, el desempeño de este papel demanda la concurrencia de una serie de exigencias, pues en otro caso se convierte, como en algunos supuestos se observa, en aparato de agitación popular y en órgano de enfrentamiento con la respectiva Corporación municipal, en vez de ser un instrumento de incitación a ésta y de fiscalización de su actuación de acuerdo con la legalidad, es decir, en vía de participación. En este sentido, consideramos como exigencias mínimas:

1. Comprender un número importante de vecinos, para de esta forma poder reflejar el sentir de la mayoría de los habitantes de la respectiva área.

2. ${ }^{\text {a }}$ Pretender fines de interés común para los asociados. Bien taxativamente enumerados o formulados de una manera genérica.

3. ${ }^{\mathrm{a}}$ Excluir de sus motivaciones y de sus reivindicaciones la intencionalidad política de un signo determinado.

4. ${ }^{a}$ Procurar que en sus peticiones y en su relación con la Corporación domine la objetividad y el buen sentido, como única forma de lograr convertirlas en realidad, lo que significa que las reivindicaciones que se planteen deben estar fundamentadas y estudiadas debidamente.

5. ${ }^{\mathrm{a}}$ Plantear las peticiones de forma posibilista y no radicalizada, para conseguir lo más que sea factible, sin aferrarse a posturas de rigidez e intransigencia.

Estas directrices estimamos que caracterizan a las asociaciones de vecinos, que pueden desarrollar una labor fecunda y trascendental, y a éstas es a las que nos referiremos en diversos momentos, por entender que pueden dar un juego altamente positivo en la dinámica de las comunidades vecinales.

Por último, en cuanto a los métodos de articulación de la participación, nuestra atención se va a centrar en cuatro, que si bien no son los únicos, sí son los principales:

a) Exposición al público de proyectos y planes, de forma que puedan ser conocidos y que puedan ser entendidos por los posibles 
afectados, lo que suscita problemas, tanto del lugar de exposición de los mismos, como de la forma de presentación de ellos, así como del período de su exposición. Supone, en definitiva, y esto quiero subrayarlo, que se debe tender a lograr que de verdad sean conocidos $\mathrm{y}$, como consecuencia, se pueda realmente opinar sobre su contenido. Es decir, que no se trate de cumplir simplemente un mero trámite formal de información, que es lo que habitualmente sucede; con lo cual nadie se entera y después los que protestan lo hacen con razón, por estimar que se les ha ocultado para que no se puedan formular oposiciones o críticas en tiempo hábil.

Por otra parte, es importante, igualmente, el que se cuide la selección de los funcionarios encargados de informar y de aclarar dudas a los posibles interesados; para lo cual se debe procurar que en aquéllos concurra la doble cualidad de preparados desde el punto de vista técnico y con sensibilidad social para mantener una correcta relación con el público.

Por último, creemos, y lo creemos firmemente, pues llevamos muchos años propugnándolo, que frente a la creencia lamentablemente bastante generalizada de que todo vecino es un potencial opositor ante las iniciativas municipales, por cuyo motivo lo procedente es escamotearle los datos, dificultarle la información y mantenerle alejado lo más posible de los propósitos municipales, hay que concebir al vecino como un colaborador necesario, cuyas ideas, cuyas críticas y cuyas oposiciones pueden enriquecer y pueden perfeccionar los proyectos municipales, acomodándolos no sólo a sus necesidades, sino también a sus deseos.

b) Reuniones y Mesas Redondas en las que se informe sobre los propósitos y sobre los proyectos municipales y en las que se puedan recoger sugerencias de los asistentes. Reuniones y Mesas que deben responder a las siguientes directrices:

1." Celebrarse antes de adoptar las correspondientes decisiones o acuerdos, pues en otro caso implican una farsa y un engaño.

2. $\quad$ Organizarse en los lugares más apropiados - municipales o no- para facilitar la asistencia y el debate. Es decir, lo mismo pueden tener lugar en locales de la Corporación, como en propios de las asociaciones de vecinos, de entidades, etc.

3. Anunciarse debidamente, para que sean conocidas y así 
puedan asistir cuantos estén afectados directa o indirectamente por la cuestión objeto de exposición y debate.

4. ${ }^{a}$ Desenvolverse con orden y con respeto a todos los asistentes, cuidando que puedan intervenir cuantos lo deseen, así como también el que se proporcione toda clase de explicaciones que sean solicitadas.

5. Pretender no una simple aceptación al proyecto o plan, sino el perfeccionamiento de éstós, lo que puede implicar cambios sustanciales, y no sólo de detalle, en el contenido de los mismos. En este sentido, es importante que por todos los representantes municipales: políticos y funcionarios, se adopte una postura de sincera humildad y una actitud de auténtica comprensión; lo que, en definitiva, significa predisposición para escuchar, para acoger iniciativas, para estudiar las propuestas que se formulen y para incorporarlas, si es factible, al proyecto expuesto. Posición que, evidentemente, es muy distinta de la que con frecuencia se observa, de clara oposición a dichas iniciativas y propuestas, por considerar que entrañan censuras, críticas y juicios desfavorables para los autores de tal proyecto. Posición que tiene su raíz en la creencia equivocada, que también en muchas ocasiones hemos puesto de relieve, de que se posee la cualidad de la infalibilidad para detentar el poder o por tener una titulación determinada.

c) A través de encuestas para conocer las necesidades, para detectar las aspiraciones y para averiguar los deseos de los vecinos; las que se entiende que deben también responder a unas directrices mínimas:

1. Emplearse cuando se trate de cuestiones de interés general.

2. ${ }^{a} \quad$ Cuidar mucho la redacción de las preguntas, que deben ser claras, que deben ser concretas y que deben ser comprensibles; así como también la forma de contestar, que debe ser lo más simple y lo más sencilla posible, para que no exista posibilidad de equivocaciones.

3. ${ }^{a}$ Adoptar en la distribución de las encuestas y en su recogida la modalidad más apropiada a cada caso: bien directamente por los servicios municipales en los domicilios de los encuestados; bien a través de las asociaciones de vecinos, entidades, etc.

4. Analizar con objetividad y con rigor los datos aportados, 
no escamoteando, ni alterando, ni adulterando éstos cuando no coincidan con los propósitos municipales.

5. Divulgar con veracidad los resultados para que puedan ser conocidos por los participantes en la encuesta.

6. ${ }^{\text {a }}$ Tener en cuenta tales resultados al adoptar la pertinente decisión; lo que supone, tanto rectificar el proyecto de acuerdo con los mismos, como el suspenderlo si esto no es viable desde el punto de vista técnico, o financiero u organizativo.

d) Celebración de actos públicos a nivel de distrito o de barrio, en los que intervengan representantes municipales y en los que se puedan recoger las opiniones y los criterios de los participantes, que sirvan de base para la elaboración de los correspondientes proyectos, los que después deberán someterse a debate en las citadas Reuniones y Mesas Redondas. Estos actos, igualmente, podrían ser útiles para la prospección de necesidades comunitarias y para concretar las modalidades de su satisfacción.

Por último, hay que destacar que quizá se piense que con estos métodos de articulación que se proponen se dificultará aún más el funcionamiento corporativo, alargando los plazos previos a los acuerdos. Entendemos que no, pues lo que se pretende es que los plazos de información hoy vigentes, que suelen ser inoperantes y que además después se prolongan con las impugnaciones y con los recursos, sean aprovechados para el empleo de estos métodos, que sin duda harían disminuir el número de impugnaciones que se formulasen, así como también el de recursos que se interpusiesen.

\section{B) Participación en el control de las actuaciones municipales}

Creemos que el protagonismo ciudadano en su vía de participación no se agota con la intervención previa, ni tampoco con la actuación a través de los representantes políticos. Estimamos - como anticipamos- que ha de complementarse con su acceso al control de las actuaciones municipales, en cuya modalidad, los dos centros de atención, en nuestro criterio, son, por una parte, los procedimientos para llevarse a cabo; y, por otra parte, los métodos de articulación de la misma.

En primer lugar, en cuanto a los procedimientos, consideramos como principales los cuatro siguientes: 
1. Exposición de las memorias de actividades y de las rendi. ciones de cuentas, en las que en forma accesible, sencilla, clara y comprensible para el vecino, se le informe:

- de lo que se ha hecho y cómo se ha hecho;

- de lo que realmente se ha conseguido, y

- de lo que ha costado cada una de las principales actuaciones municipales.

2. Informes breves periódicos sobre las actuaciones en curso y concluidas, distribuidas territorialmente, para que el vecino pueda tener una idea clara:

- de lo que se hace en su beneficio;

- de lo que cuesta, y

- de lo que él aporta.

3. Informes a la prensa, de carácter sintético, similares a los anteriores, para que, en base a los mismos, los periodistas puedan redactar reportajes que ilustren a los lectores.

4. Reuniones informativas periódicas, dirigidas por representantes municipales, en las que:

- se dé cuenta de la labor realizada y en desarrollo;

- se aclaren cuantas dudas existan y se responda a cuantas preguntas se formulen, $y$

- se recojan las opiniones y juicios de los asistentes relativos a dichas actuaciones.

Por último, con respecto a los métodos para articular el control social de la actividad municipal, entendemos que los principales son estos tres:

1.' A través de las asociaciones de vecinos, de amas de casa, etcétera, que a su vez pueden adoptar estas fórmulas:

- Informándoles de los acuerdos adoptados por los órganos corporativos.

- Celebrando con sus representantes reuniones para informarles de las decisiones adoptadas y de las actuaciones realizadas. 
- Invitando a sus representantes que asistan a las sesiones públicas de la Corporación.

2. Mediante las Juntas de Distrito o de Zona, convocando en ellas reuniones periódicas y dando en las mismas cuenta de las realizaciones y del estado de las obras en construcción. En los Municipios en los que no existan tales Juntas, que son la inmensa mayoría, se pueden sustituir por reuniones en los barrios con los Concejales delegados.

3. Mediante reuniones-coloquio entre representantes municipales y vecinos sobre cuestiones determinadas y concretas, que permitan a éstos un conocimiento profundo y real de la problemática de dichas cuestiones, y que hagan posible que aquéllos sepan cuál es el pensamiento, el punto de vista y los criterios de los vecinos con respecto a tales cuestiones.

\section{COLABORACION CIUDADANA}

El protagonismo ciudadano no debe ni puede limitarse -como anticipamos- a proyectarse en la participación en las dos modalidades expuestas. Pues si bien es cierto que ésta entraña un derecho y una responsabilidad cívica, existe otra forma que implica una obligación social sumamente trascendente que las complementa: es la colaboración ciudadana, que da un significado integral al papel de la mujer y del hombre dentro del ser y del existir de la comunidad vecinal a la que pertenece.

Ahora bien, ¿qué entendemos por colaboración ciudadana? La colaboración ciudadana la concebimos como el compromiso de cooperación consciente que pesa sobre todo integrante de la comunidad municipal, distinto del que le viene impuesto por una norma de policia o por una ordenanza fiscal, y que puede revestir tres modalidades distintas y complementarias:

1. En la realización de obras y en la implantación de servicios municipales, que puede adoptar fundamentalmente tres fórmulas distintas:

- A través de iniciativas, tanto individuales como de grupo o de asociaciones, entidades, etc., dirigidas a sugerir su realización o implantación. 
- Mediante asistencia que se brinda para dicha realización o implantación, bien de tipo personal, de carácter material o de índole técnica (en especial de los colegios profesionales).

- Advirtiendo los defectos o los fallos que observen en su ejecución o implantación, tanto por medio de escritos individuales o colectivos, o a través de peticiones de las asociaciones y de las entidades o de informes técnicos de los grupos correspondientes.

2. En el funcionamiento de los servicios municipales, que puede adoptar básicamente cuatro formas distintas:

- Cooperando en su desarrollo, tanto en forma individual (cumpliendo estrictamente las Ordenanzas y los Bandos), como de modo colectivo, a través de las asociaciones y entidades, formulando propuestas y vigilando el cumplimiento de las normas que rigen su actuación.

La cooperación en este área puede darse, en especial, en los servicios de limpieza viaria y de recogida domiciliaria de basuras; en los de tráfico urbano, tanto de vehículos como de peatones; en la reducción de la contaminación atmosférica y en la acción de ornato y embellecimiento de la ciudad.

- Sugiriendo cómo perfeccionar dicho funcionamiento, a través de iniciativas individuales, de las asociaciones y entidades, tanto aportando ideas originales, como brindando experiencias de resultados satisfactorios en otras poblaciones.

- Denunciando los defectos que observen, mediante reclamaciones individuales o de asociaciones y entidades, y a través de escritos publicados en la prensa o difundidos por la radio.

- Apoyando moralmente a la Corporación, cuando se enfrente con grupos de presión, en especial en orden a la especulación del suelo.

3." En la relación con los servicios municipales, que pueden, a su vez, revestir interés de tres formas distintas:

- Prestándoles ayuda para facilitar su actuación, la que puede ser, primordialmente, tanto de carácter económico como de índole técnica. 
- Aportando ideas para perfeccionarles, adecuándoles a las exigencias de cada momento.

- Denunciando sus fallos ante las autoridades, para que sean corregidos y se evite su repetición.

\section{CONCLUSION}

Y llegamos al final de nuestra disertación, para no cansar vuestra paciencia y para no agotar vuestra benevolencia. A lo largo de la exposición el objetivo perseguido ha sido reflexionar en voz alta, para destacar cómo en el momento actual, independientemente de las necesarias modificaciones estructurales y funcionales que se introduzcan en las Corporaciones municipales para adecuarlas a las exigencias de la España de 1977, es preciso que simultáneamente se acometa un cambio esencial en su relación con los vecinos, para propiciar y para hacer factible su integración plena con su respectiva Corporación.

Cambio trascendental que requiere, como decíamos al comienzo, un gran esfuerzo de imaginación, una voluntad de trabajo, un espíritu de solidaridad y un ánimo de comprensión, tanto por parte de los políticos como por parte de los funcionarios. Y dentro de éstos, en especial, de los componentes de los Cuerpos Nacionales, que por su responsabilidad directiva han de sugerir ideas a los políticos para articular sus propósitos y han de inspirar modelos de comportamiento a los funcionarios que trabajan con ellos.

Por otra parte, estimamos que con nuestra exposición se ha puesto de manifiesto la ineludible necesidad de la participación ciudadana, concebida como derecho y como responsabilidad cívicas; así como también lo indispensable que resulta la colaboración ciudadana, entendida como obligación social. $\mathrm{Y}$ ambas configuradas como compromiso público ante la respectiva comunidad vecinal, pues en la hora actual, y en mayor grado en el futuro inmediato, se precisa contar con todas las aportaciones y se requiere disponer de todas las asistencias de los integrantes de aquélla para hacer frente a las crecientes, a las complejas y a las heterogéneas necesidades sociales.

Por cuanto la comunidad municipal, como microcosmos, no es sólo el marco de convivencia de un conjunto de mujeres y de hombres, sino que es también, y al mismo tiempo, el ámbito físico de 
satisfacción de necesidades materiales y de aspiraciones ideales de aquéllos, y es igualmente un área determinada y concreta para la realización de una empresa de vida común de los mismos de acuerdo con un modelo dado. La convivencia, la satisfacción de necesidades y de aspiraciones y la realización de esta empresa común demandan, como queda dicho, la intervención activa y la contribución plena de cuantos componen dicha comunidad vecinal.

Intervención y contribución que requieren, por una parte, una mentalización del ciudadano de su exacto papel dentro de dicha comunidad vecinal, en la que no sólo ha de participar y ha de colaborar, sino que ha de concebirla y ha de sentirla como un mundo propio, y como consecuencia entender que todos los aspectos de ella le afectan vitalmente y que de todos los aspectos de la misma ha de preocuparse emotiva y racionalmente de una manera permanente y de un modo auténtico. Significa, pues, que ha de sentirse integrado en ella de una forma consciente y total, lo que implica, en definitiva, que ha de tener un verdadero espíritu cívico.

Intervención y contribución que, por otra parte, demandan que los dirigentes de la comunidad vecinal, las autoridades municipales, fomenten las mismas y las hagan factibles por su manera de actuar, que propicie la síntesis de aspiraciones, la sincronización de esfuerzos y la aglutinación de deseos e inquietudes.

Esta es, en conclusión, la gran meta que hemos de proponernos en la hora actual: crear un clima de entendimiento, articular unos cauces de protagonismo verdadero y motivar unas ilusiones comunes para lograr que la diversidad de creencias, la pluralidad de ideologías y la heterogeneidad de sentimientos se transformen en unos mínimos denominadores comunes, en los que se pueda asentar la participación real y la colaboración efectiva de esas mujeres y de esos hombres que forman la comunidad municipal. Para lo cual es ineludible esforzarse en la obra de resaltar y de potenciar aquello que les una, así como también en la tarea de soslayar y de marginar cuanto pueda separarles. Por cuanto la comunidad municipal sólo podrá subsistir, sólo podrá hacer frente a las mencionadas crecientes necesidades sociales y sólo podrá prosperar si consigue convertir a la multiplicidad de sus componentes en un conjunto integrado de seres que sienten, que piensan, que se manifiestan y que actúan al unísono, independientemente de la diversidad de sentimientos, de pensamiento y de intereses individuales de cada uno de ellos. Este es el gran reto al que han de hacer 
frente los dirigentes municipales: sumar esfuerzos, restar diferencias, multiplicar ilusiones y dividir antagonismos, y este reto han de saber vertebrarlo mediante la participación verdadera y a través de la colaboración efectiva. El conseguirlo o el no alcanzarlo es el auténtico test de su capacidad directiva. 